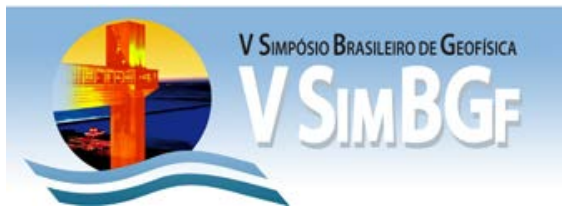

\title{
Petrofísica laboratorial no suporte à exploração e caracterização de reservatórios
}

Edmilson Helton Rios ${ }^{1,2}$; Paulo Frederico de Oliveira Ramos ${ }^{1,2}$; André Luiz Martins Compan ${ }^{1}$; Rodrigo Surmas ${ }^{1}$; Heitor Victor Ribeiro Camargo $^{1}$; Dario Abilio Cruz $^{1}$; Rodrigo Skinner'; Vinicius de França Machado'; Irineu Figueiredo ${ }^{2}$; Giovanni Chaves Stael ${ }^{2}$ ${ }^{1}$ Cenpes/Petrobras; ${ }^{2}$ Geofísica/Observatório Nacional

Copyright 2012, SBGf - Sociedade Brasileira de Geofísica

Este texto foi preparado para a apresentação no V Simpósio Brasileiro de Geofísica, Salvador, 27 a 29 de novembro de 2012. Seu conteúdo foi revisado pelo Comitê Técnico do $V$ SimBGf, mas não necessariamente representa a opinião da SBGf ou de seus associados. É proibida a reprodução total ou parcial deste material para propósitos comerciais sem prévia autorização da SBGf.

\section{Resumo}

O presente trabalho demonstra algumas importantes técnicas de petrofísica laboratorial através de um fluxo de trabalho muito comum na indústria de petróleo. Tal fluxo começa pela correta extração, seleção e limpeza das amostras; passa pela petrofísica de rotina, cujas propriedades petrofísicas básicas são mensuradas a gás, tais como densidade de grãos, volume de poros, porosidade e permeabilidade; e vai até a petrofísica especial, onde os ensaios são realizados com saturações de fluidos diversos para medidas de propriedades elétricas, pressões capilares, permeabilidades relativas, distribuição de gargantas e tamanho de poros e índices de molhabilidade. São discutidos aspectos teóricos e práticos de cada método e seus principais protocolos de medida. No contexto da exploração e caracterização de reservatórios, a importância da medida laboratorial tanto para calibração do dado de campo quanto para geração de informações indisponíveis em campo é enaltecida ao longo do texto.

\section{Introdução}

O estudo das propriedades físicas das rochas (ígneas, metamórficas ou sedimentares) é uma área bastante interdisciplinar podendo envolver inúmeros métodos físicos (Schon, 2004). No caso das rochas reservatório, dois termos se distinguem: física de rochas e petrofísica. A física de rochas é focada nas propriedades físicas que estabelecem uma relação com os atributos sísmicos, tais como velocidades compressionais e cisalhantes, módulos elásticos e de rigidez, entre outros; sendo, por isso, também denominada petrossísmica (Vasquez et al., 2011). Já a petrofísica é responsável pela caracterização dos fenômenos físicos e químicos relacionados à estrutura porosa e sua interação com os fluidos presentes. Ela participa da avaliação do potencial de exploração e explotação das jazidas fornecendo parâmetros para a determinação da sua capacidade de armazenamento e de produção (Schon, 2004). A investigação petrofísica ocorre na escala de campo, por meio da perfilagem geofísica de poço, ou na escala laboratorial, via medições em amostras realizadas em equipamentos de bancada. Existem benefícios particulares em cada uma das modalidades, sendo que a integração entre as duas (integração rocha-perfil) é fundamental para construção de um modelo geológico mais realista e melhor prever o comportamento do reservatório (Freire et al., 2010). O fluxo convencional de trabalho da petrofísica laboratorial inicia-se com a obtenção de amostras de rocha reservatório representativas. Ainda que existam ensaios realizados em amostras preservadas, o mais comum é limpá-las e secá-las para as análises de rotina, cujo principal objetivo é a medição a gás das propriedades permoporosas, etapa conhecida como petrofísica básica. Para algumas amostras selecionadas, ensaios mais sofisticados são realizados sob diferentes condições de saturação de fluidos, etapa conhecida como petrofísica especial (Tiab \& Donaldson, 2004). Apesar de serem ensaios mais longos e onerosos, seus resultados são indipensáveis, pois geram informações mais próximas às condições de reservatório.

\section{Extração e seleção de amostras}

As amostras de rocha reservatório são obtidas em operações de testemunhagem ou por amostragem lateral do poço. Os testemunhos são cilindros de rocha com diâmetro de 2 a 6 polegadas (pol) e comprimento contínuo podendo chegar a 20 metros. Eles são extraídos durante a perfuração de poço subtituíndo-se a broca regular por um conjunto formado por uma broca especial vazada (coroa) e um barrilete, este último responsável por acomodar a rocha cortada (Rosa et al., 2006). Por se tratar de uma operação bastante cara, a testemunhagem é feita somente em parte dos poços perfurados, sendo especialmente indicada nas etapas iniciais de exploração e desenvolvimento do reservatório. As amostras laterais são pequenos pedaços de rocha cilíndricos, denominados plugues, geralmente com diâmetro de 1 pol e comprimento de até 2 pol. A coleta é realizada por ferramentas a cabo após a perfuração do poço (Rosa et al., 2006). Numa mesma corrida, várias amostras são coletadas em diferentes profundidades, sendo que os custos dessa operação são menores que 0 da testemunhagem.

Entre as vantagens de se obter o testemunho contínuo, destaca-se a possibilidade de avaliações geológicas mais amplas sobre seu histórico de deposição. Além disso, os testemunhos podem ser imageados de forma não invasiva em tomógrafo médico (resolução próxima de 0,5 $\mathrm{mm}$ por pixel). A tomografia computadorizada de raios $X$ tem como objetivo avaliar os possíveis danos na operação de testemunhagem, a presença de heterogeneidades e fraturas, além de auxiliar no processo de seleção das amostras e posterior caracterização da rocha a partir das imagens de sua estrutura porosa (API, 1998). Além da tomografia, várias outras análises petrofísicas podem ser realizadas diretamente em testemunhos, porém os equipamentos, procedimentos experimentais e munuseio das amostras são bem mais complexos. O mais comum é a extração de plugues horizontais ou verticais do testemunho, 
geralmente com 1,5 pol de diâmetro e cerca de 2 pol de comprimento (API, 1998). A grande maioria dos equipamentos petrofísicos disponíveis no mercado são projetados para amostras com essas dimensões.

\section{Limpeza e petrofísica básica}

Antes das caracterizações petrofísicas convencionais (amostras não preservadas), os plugues são limpos para garantir a remoção completa de quaisquer fluidos e impurezas contidas no espaço poroso, resíduos de sais e hidrocarbonetos. O processo de limpeza é realizado com solventes, podendo ser através de extração contínua e desassistida empregando extratores Soxhlet, método Dean Stark ou limpeza em fluxo. Em todos os casos, a escolha do solvente utilizado nos ciclos de extração depende do tipo de resíduo que se pretende extrair e sua respectiva afinidade química com o solvente. A água conata, por ser polar, é extraída com metanol e os hidrocarbonatos, por serem apolares, são removidos com tolueno ou clorofórmio (API, 1998). O tempo de limpeza depende do método, da viscosidade dos fluidos e das propriedades permoporosas da rocha, podendo levar de semanas até alguns meses. A total remoção de resíduos salinos é confirmada através de teste químico com nitrato de prata quando não há ocorrência de precipitação de cloreto de prata. A eficiência da remoção de hidrocarbonetos pode ser acompanhada através de cintilação via fluorescência. Após a limpeza, os plugues são submetidos a estufas especiais até que estejam totalmente secos. Caso possuam argilo minerais, mais comum em arenitos, são submetidos a estufas especiais com humidade controlada, isso para que a água estrutural da argila não seque e danifique sua estrutura laminar (API, 1998). Todas as amostras são resfriadas sob vácuo em dessecadores para evitar absorção de humidade do ar.

Os ensaios de petrofísica básica ocorrem em porosímetro e permeâmetro de expansão a gás (hélio ou nitrogênio). A porosidade $(\phi)$ é calculada através da razão do volume poroso $\left(V_{p}\right)$ pelo volume total $\left(V_{T}\right)$, Eq. 1 , medidos pela aplicação direta da Lei de Boyle Mariotte para gases ideais (Schon, 2004), Eq. 2.

$$
\phi=\mathrm{V}_{\mathrm{P}} / \mathrm{V}_{\mathrm{T}}=\mathrm{V}_{\mathrm{P}} /\left(\mathrm{V}_{\mathrm{P}}+\mathrm{V}_{\mathrm{S}}\right), \quad \mathrm{P}_{\mathrm{i}} \mathrm{V}_{\mathrm{i}}=\mathrm{P}_{\mathrm{f}} \mathrm{V}_{\mathrm{f}}
$$

No porosímetro, o gás preenche a linha do equipamento e uma pequena câmara interna de referência, cuja soma dos volumes iniciais é $V_{i}$ e a pressão inicial é $P_{i}$. Assim que a pressão se estabiliza, o gás se expande isotermicamente para uma segunda câmera de volume conhecido, dentro da qual a amostra se encontra. A pressão final do sistema $P_{f}$ é reduzida na mesma proporção em que o volume ocupado pelo gás aumenta $\mathrm{V}_{\mathrm{f}}$. Empregando a Eq. 2, o volume de sólidos $\left(\mathrm{V}_{\mathrm{S}}\right)$ da matriz rochosa é obtido. A densidade de grãos ou massa específica $\left(\rho_{\mathrm{m}}\right)$ é obtido pela razão entre a massa seca $\left(\mathrm{M}_{\mathrm{S}}\right)$ e $\mathrm{V}_{\mathrm{S}}$. O $\mathrm{V}_{\mathrm{P}}$ é determinado pelo mesmo procedimento, porém o gás se expande para o interior da rocha, confinada por uma camisa de borracha dentro de uma célula de pressão (Rosa et al., 2006), tal como representado na Figura 1 . O porosímetro mede somente a porosidade efetiva uma vez que o gás não atinge os poros não conectados. No permeâmetro, o gás atravessa a amostra confinada, Fig.1, sendo que o controle da vazão do gás é realizado manualmente através de válvulas de alta e baixa pressão contidas no módulo do equipamento. Com fluxômetros e transdutores de pressão calibrados, a vazão (Q) e o diferencial de pressão do gás $(\Delta P)$ são medidos durante um fluxo estável e não compressível (Tiab \& Donaldson, 2004). Por isso, emprega-se a lei de Darcy para o cálculo da permeabilidade absoluta ao gás, tal que:

$$
\mathrm{K}=-\mu \mathrm{QL} / \mathrm{A} \Delta \mathrm{P}
$$

em que $\mu$ é a viscosidade dinâmica; $L$ o comprimento e $A$ a área da seção transversal do plugue. É importante enfatizar que não há nenhum método de perfilagem capaz de medir diretamente a permeabilidade, o que confere um status de muita relevância para tal medida laboratorial.

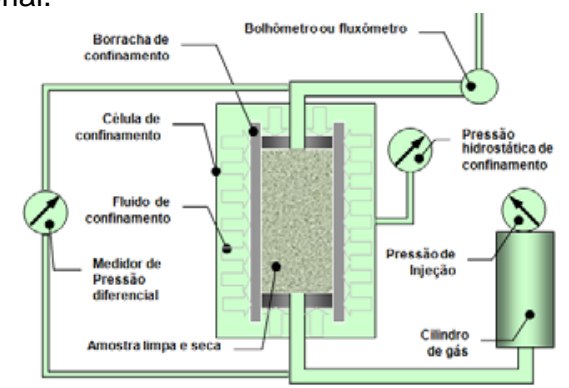

Fig. 1 - Esquema simplificado de um permoporosímetro.

Os resultados de petrofísica básica são geralmente disponibilizados a tempo de serem considerados para tomada de decisão de testes de formação, completação, canhoneio ou abandono de poço (Rosa et al., 2006). As medidas de rotina são realizadas em todos os plugues, e as informações permoporosas são imediatamente utilizadas para uma primeira determinação da qualidade da rocha reservatório, verificação ou calibração de alguns perfis e para seleção de amostras para petrofísica especial. Como regra, entre diferentes ensaios especiais, a amostra é limpa e a petrofísica de rotina é novamente realizada.

\section{Petrofísica especial}

\section{Saturação com água de formação sintética}

A primeira etapa da maioria dos ensaios de petrofísica especial é a preparação da água de formação sintética para saturação inicial das amostras. Tal saturação pode ser realizada por injeção de água na amostra confinada em célula de pressão ou em centrífugas. No entanto, o mais comum é a utilização de um sistema capaz de saturar várias amostras ao mesmo tempo, geralmente composto por duas garrafas de pressão interconectadas. Um conjunto de plugues secos é alojado no interior de uma delas e submetido a um intenso vácuo por algumas horas para remoção do ar contido nos poros. Em seguida, a solução é injetada e posteriormente pressurizada a pelo menos 2.000 psia, por bombeamento hidráulico de óleo, o qual empurra um êmbolo (no interior da segunda garrafa), que por sua vez pressiona a solução para o interior do espaço poroso (API, 1998). O sistema é então mantido pressurizado por várias horas. Tal procedimento garante uma boa saturação da 
amostra, preenchendo inclusive os micro poros de mais difícil acesso. Uma vez que a massa seca $\left(M_{s}\right)$ e a massa saturada ou molhada $\left(\mathrm{M}_{\mathrm{m}}\right)$ da rocha, e a densidade da água de formação $\left(\rho_{\mathrm{w}}\right)$ são facilmente mensuradas, o volume poroso por peso $\left(\mathrm{V}_{\mathrm{PP}}\right)$ e a saturação de água $\left(S_{w}\right)$ são obtidos, tal que:

$$
\mathrm{V}_{\mathrm{pp}}=\left(\mathrm{M}_{\mathrm{m}}-\mathrm{M}_{\mathrm{s}}\right) / \rho_{\mathrm{w}} \quad \mathrm{S}_{\mathrm{w}}=\mathrm{V}_{\mathrm{pp}} / \mathrm{V}_{\mathrm{p}}
$$

\section{Propriedades elétricas e pressão capilar membrana}

As propriedades elétricas de um plugue geralmente são medidas concomitantemente a obtenção das curvas de pressão capilar membrana (PCM) em um equipamento denominado eletrocapilarômetro, Fig. 2. Tal como o permeâmetro, o plugue é inserido em uma camisa de borracha dentro de uma célula de confinamento. Após injeção de alguns volumes porosos de água de formação, a resistência da amostra totalmente saturada com água é medida e a correspondente resistividade $\left(R_{0}\right)$ é obtida.

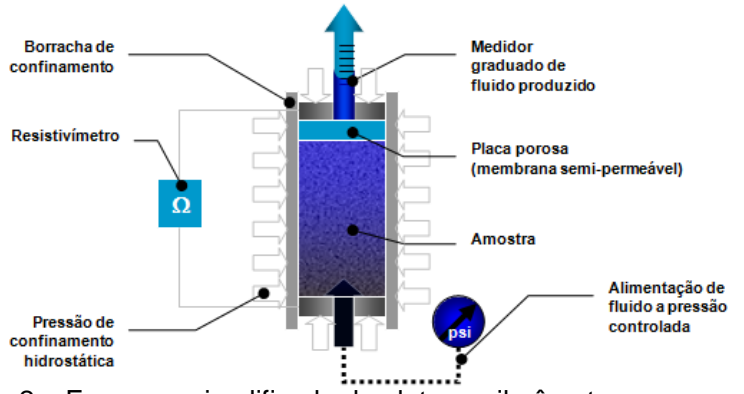

Fig. 2 - Esquema simplificado do eletrocapilarômetro.

Numa segunda etapa o sistema é alimentado por óleo sob pressão controlada para deslocar a água da amostra, em um processo denominado drenagem. No topo da amostra há uma placa porosa permeável apenas ao fluido molhante, que saturava a amostra inicialmente (neste caso a água). Com isto o fluido deslocante (neste caso o óleo) não é produzido. A pressão aplicada na amostra é contrabalanceada pela pressão capilar fazendo a produção de fluido deslocado se estabilizar quando a pressão capilar for igual à pressão aplicada ao óleo (Tiab \& Donaldson, 2004). Com o fluido deslocado medido em uma pipeta graduada é possível saber a saturação dos fluidos no interior da amostra em cada momento. Durante a aplicação seqüencial dos diversos níveis de pressão capilar, aguarda-se a estabilização da produção e da medida de resistência. Dessa forma, obtém-se a resistividade da amostra parcialmente saturada com água $\left(R_{T}\right)$ para aplicação da lei de Archie:

$$
S_{w}^{n}=R_{o} / R_{T}=a / \phi^{m} \times R_{w} / R_{T}
$$

em que $n$ é o expoente de saturação, $m$ o coeficiente de cimentação aparente, ' $a$ ' é um coeficiente litológico e $R_{w}$ a resistividade da água de formação (Schon, 2004). A partir da lei de Archie, define-se o Fator de Formação $(F F)$, a tortuosidade $(\tau)$ e o Índice de Resistividade (IR):

$$
F F=R_{o} / R_{w}=a / \phi^{m}=\tau / \phi \quad I R=1 / S_{w}^{n}=R_{T} / R_{o}
$$

A obtenção laboratorial desses parâmetros é de extrema importância para calibração dos perfis de resistividade e para estimativa de parâmetros petrofísicos de importância, a exemplo de conectividade e permeabilidade, principalmente em modelos de petrofísica teórica e digital.
A saturação de água na amostra, uma vez estabilizada a produção, pode ser registrada em função da pressão capilar em cada incremento de pressão de injeção aplicado. Com isso, obtém-se a curva de pressão capilar de drenagem óleo-água, curva em vermelho na Fig. 3. Quando a saturação de água não for mais reduzida, mesmo com incrementos significativos de pressão, diz-se que a amostra atingiu sua saturação de água irredutível (Swi), assíntota da curva de drenagem (Rosa et al., 2006). Uma simulação do processo de produção de um reservatório pode ser posteriomente realizada injetandose gradualmente água na amostra na condição de Swi. Para isso a membrana anteriomente hidrofílica deve ser substituída por uma hidrofóbica, permitindo a passagem apenas do óleo. Nesse caso, a medida que a produção de óleo se estabiliza, mesmo com aumentos significativos de pressão capilar, diz-se que a mostra atingiu a saturação de óleo residual Sor (assíntota da curva de embebição).

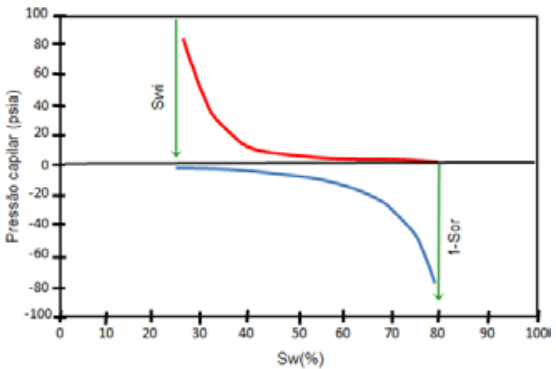

Fig. 3 - Curvas de pressão capilar durante drenagem (vermelho) e embebição (azul).

Curvas de pressão capilar não podem ser obtidas em campo de forma direta. Entre suas inúmeras aplicações destacam-se a análise de qualidade de rocha e desempenho de recuperação de óleo. A PCM é o método mais confiável para obtenção dessas curvas, no entanto sua montagem é bastante complexa e o ensaio é extremamente longo. A pressão capilar centrífuga (PCC) é um método alternativo, bastante prático e rápido.

\section{Pressão capilar centrífuga}

Inicialmente saturada com o fluido a ser deslocado, a amostra a ser ensaiada em centrífuga é colocada em um copo imersa com fluido deslocante, Fig. 4. Este sistema é rotacionado de modo que, por diferença de densidades, é criado um campo de pressões responsável pela força de deslocamento dos fluidos. O fluido que está saturando a amostra tende a ser deslocado para uma das faces do copo (se afastando ou se aproximando do eixo de rotação dependendo da relação de densidades entre os fluidos) e o fluido deslocante ocupa o espaço deixado pelo fluido deslocado (Tiab \& Donaldson, 2004). a)

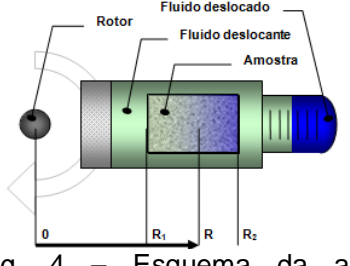

b)

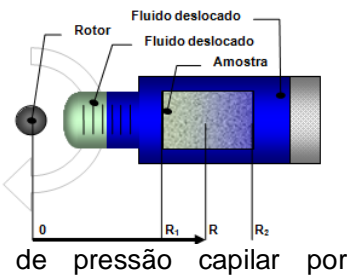
centrifugação: processos de a) drenagem e b) embebição. 
O volume de fluido deslocado é medido e assim é possível obter a saturação da amostra. Na centrífuga as pressões capilares variam ao longo do eixo da amostra em função da distância do centro de rotação (força centrípeta). A pressão capilar na drenagem e na embebição são dadas respectivamente:

$$
P_{c}=\omega^{2} \Delta \rho\left(R_{2}^{2}-R^{2}\right) / 2 \quad P_{c}=\omega^{2} \Delta \rho\left(R_{1}^{2}-R^{2}\right) / 2
$$

Em função da variação de pressão capilar, a saturação também não é homogênea ao longo da amostra. Esta é uma das limitações da técnica de PCC uma vez que não há relação direta entre a saturação média medida e a pressão capilar calculada pela rotação.

Para a obtenção da saturação em um determinado ponto são utilizados métodos numéricos. Vários métodos são propostos na literatura sendo que um bastante utilizado é o método de Skuse. A saturação média medida é a média ponderada de todas as saturações do meio poroso:

$$
\mathrm{S}_{\mathrm{M}}=\int \mathrm{S}(\mathrm{Pc}(\mathrm{R})) \mathrm{dV} / \mathrm{V}_{\mathrm{T}}
$$

em que (S) é a saturação pontual, função da pressão capilar (Pc), que por sua vez é função da posição $(R)$. A inversão da Eq. 9 pode ser bastante complicada dependendo da relação utilizada para a pressão capilar em função da posição na amostra. O método mais simples é o Hassler-Brunner que desconsidera efeitos radiais e gravitacionais sobre a pressão capilar ao longo da amostra (Tiab \& Donaldson, 2004). Este método é válido para amostras pequenas centrifugadas longe do eixo de rotação. O método de Skuse desconsidera os efeitos gravitacionais mas leva em consideração os efeitos radiais para obter a saturação em um ponto a partir da saturação média. As curvas de pressão capilar são calculadas pelo método de Skuse para a face de entrada do fluido deslocante na amostra a partir dos volumes de produção estabilizados e lidos a cada patamar de rotação (ou pressão capilar).

\section{Permeabilidade Relativa}

Existem dois principais métodos para determinação da permeabilidade relativa: o de regime permanente e o método transiente. O método permanente consiste em injetar simultaneamente água e óleo na amostra de rocha, Fig. 5, em proporções crescentes de água, mantendo-se constante a vazão total injetada. Para cada proporção utilizada, aguarda-se que o estado estacionário deste escoamento seja atingido, caracterizado pela estabilização do diferencial de pressão e de produção de fluidos. Nesta situação, aplica-se a lei de Darcy para cada uma das fases, obtendo-se as respectivas permeabilidades efetivas. Já o método transiente consiste em deslocar o fluido que satura o meio poroso injetando outro fluido a vazão constante ou pressão constante. Os efluentes produzidos ao longo deste deslocamento, juntamente com o diferencial de pressão obtido entre a entrada da amostra e a saída, constituem-se nos dados que são utilizados no cálculo das curvas de permeabilidade relativa. A abordagem de cálculo utilizada nos ensaios em regime transiente foi inicialmente proposta por Welge e recebeu melhorias como a de Johnson Bosller e Naumann e Jones-
Roszelle. A grande vantagem do método permanente reside na simplicidade dos cálculos. No entanto, o processo de obtenção do equilíbrio é demorado e necessita ser repetido para cada proporção de fluidos injetada, ocasionando uma duração média, para a conclusão de um ensaio, 30 vezes maior que o regime transiente. Porém, como vantagem ainda, é possível obter informações de permeabilidade relativa para valores de saturação de água inferiores aos que seriam obtidos por um teste similar conduzido em regime transiente, bastando para isto, reduzir a proporção de água injetada.

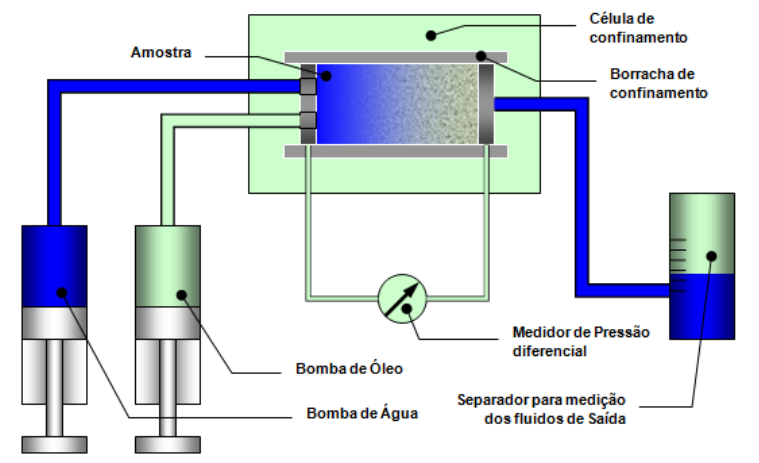

Fig. 5 - Esquema simplificado do equipamento de análise de permeabilidade relativa água-óleo.

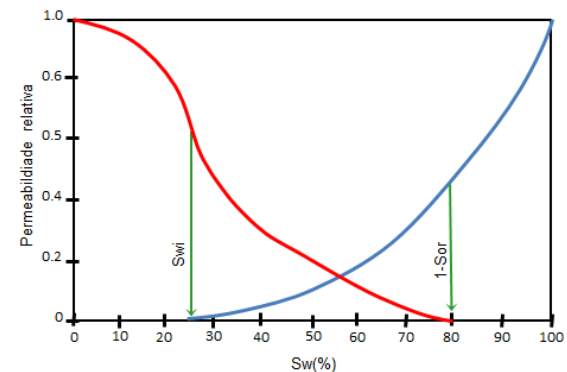

Fig. 6 - Curvas de permeabildiade relativa a água (azul) e ao óleo (vermelho).

A figura 6 ilustra a obtenção de curvas de permeabilidade água-óleo, pelo regime transiente. Na prática, o primeiro passo do teste é confinar a amostra em uma célula de pressão e medir a permeabilidade absoluta a água, Eq. 3, para verificar os resultados de permeabilidade absoluta ao ar e possíveis interações fisico-químicas entre a rocha e a água de formação (inchamento de argilas, por exemplo). Em seguida, a amostra é drenada com óleo até a saturação de água irredutível (via centrífuga ou em membrana porosa) e a permeabilidade efetiva ao óleo no Swi é calculada. Em seguida desloca-se o óleo pela injeção de água de formação sintética a vazão constante até o estado de saturação residual de óleo (Sor) com medição de produção de óleo em um separador e da pressão diferencial ao longo do teste, Fig. 5. Depois mede-se a permeabilidade efetiva à água no Sor. Utilizando-se processos de otimização o problema inverso é resolvido para obtenção das curvas de permeabilidade relativa óleo-água em função das curvas de produção de óleo e diferencial de pressão. 


\section{Capilarimetria por intrusão de Mercúrio}

O ensaio de capilarimetria por injeção de mercúrio é destrutivo e por isso se extrai apenas um pequeno fragmento da rocha, cuja geometria não necessita ser regular. O fragmento limpo e seco é acondicionado em um pequeno vaso de intrusão (denominado penetrômetro) que se acopla à uma câmara interna do porosímetro de mercúrio, onde se faz vácuo, isso para que 0 ar atmosférico não atrapalhe a posterior penetração do mercúrio. Logo após, completa-se o vaso com mercúrio até o nível de referência da câmara, obtendo-se neste ponto o volume da amostra, aplica-se o primeiro patamar de pressão, aguardando o período de estabilização. Os patamares de pressão seguintes são gradativamente aplicados, sempre aguardando a estabilização da intrusão, podendo-se chegar a um limite de até 60000 psia dependendo do equipamento. A curva de pressão capilar por mercúrio é obtida com o registro da saturação de mercúrio $\left(\mathrm{S}_{\mathrm{Hg}}\right)$ para cada pressão de intrusão aplicada (Tiab \& Donaldson, 2004). Considerando-se que as gargantas de poros são capilares cilíndricos, a curva de distribuição de raios de gargantas de poros também pode ser obtida empregando-se a equação de Laplace:

$$
\mathrm{P}_{\mathrm{c}}=(2 \sigma \cos \theta) / \mathrm{r}
$$

em que $P_{c}$ é a pressão capilar; $\sigma$ a tensão superficial, $\theta 0$ ângulo de contato; $r$ o raio de garganta de poros.

O ensaio de intrusão de mercúrio determina a distribuição de volume de poros acessíveis a uma determinada pressão. Esta definição pode ser mais bem compreendida observando-se a Figura 7a. Nesta representação o volume 4 só é acessível quando se atinge um nível de pressão capaz de vencer a pressão capilar exercida pela garganta que separa o volume 3 e o volume 4. Quando esta pressão é atingida, todo o volume 4 é preenchido, pois neste espaço não há outra garganta que empeça o preenchimento (garganta menor em raio que requeira uma pressão maior do que a que já foi atingida). A distribuição de garganta de poros normalmente não é tão deformada como foi apresentada no exemplo da Figura 7b, pois poros maiores têm grande chance de estarem conectados por gargantas maiores e poros menores por gargantas menores. Então a "distribuição de volume de poros acessíveis a uma determinada pressão ou através de um determinado raio de garganta de poro" é normalmente próxima a "distribuição de garganta de poros".

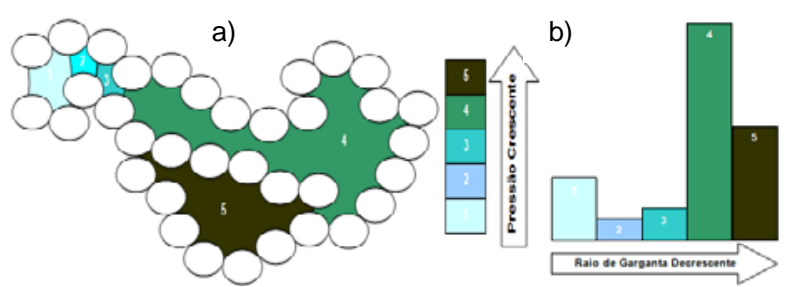

Fig. 7 - a) Representação de um processo de intrusão capilar e b) respectiva distribuição de gargantas de poros.

\section{Ressonância Magnética Nuclear}

A ressonância magnética nuclear (RMN) de baixo campo mede a relaxação magnética dos fluidos confinados no espaço poroso (Rios, 2011). As curvas de relaxação dos fluidos de um plugue são medidas em um espectrômetro de baixo campo, geralmente $2 \mathrm{MHz}$, e invertidas pela transformada inversa de Laplace para obtenção dos espectros ou distribuições de tempos de relaxação $T_{1}$ e $\mathrm{T}_{2}$, proporcionais a razão superfície (S) volume de poro (V) de modo que:

$$
1 / \mathrm{T}_{1,2} \approx \rho_{1,2} \mathrm{~S} / \mathrm{V}
$$

em que $\rho_{1,2}$ é a relaxatividade superficial para $T_{1}$ e para $\mathrm{T}_{2}$, a qual depende da interação do fluido com a superfície interna do poro. Calibrando-se o sinal de RMN, a área sob o espectro de relaxação representa a porosidade total da rocha e cortes bem localizados podem gerar informações quantitativas sobre micro, meso e macroporosidade. Enquanto a porosimetria por mercúrio fornece uma distribuição de gargantas de poros, o RMN fornece uma distribuição de tamanho de poros. Para uma geometria cilíndrica, por exemplo, V/S =r/3, em que r é o raio do poro.

Dentre os vários ensaios que podem ser realizados, o mais tradicional consiste na obtenção do tempo de relaxação de corte que delimita a fronteira entre fluido livre (produzível) e o fluido irredutível (retido pela capilaridade do reservatório), informação útil para interpretação dos perfis de RMN. Nesse ensaio, o ponto de intersecção entre a assíntota da curva de porosidade acumulada na condição de saturação irredutível ar-água (Swi) e a curva de porosidade acumulada na condição de saturação total $(\mathrm{Sw}=100 \%)$ corresponde ao valor de corte, Fig. 8. A área sob o espectro de RMN (Sw=100\%) correspondente a região acima do valor de corte está relacionada ao volume de fluido livre da amostra. A área abaixo desse valor está associada ao volume de fluido irredutível, preso por forças capilares ou adsorvido em argila (Rios, 2011).

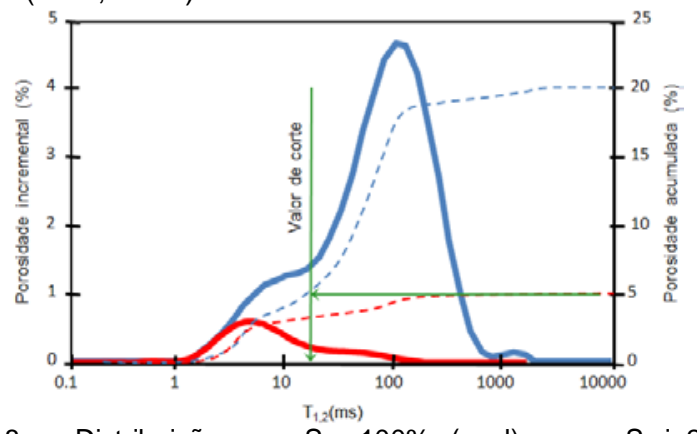

Fig. 8 - Distribuições no $\mathrm{S} w=100 \%$ (azul) e no $\mathrm{Swi}=25 \%$ (vermelho) e consecutiva obtenção do valor de corte.

\section{Índices de molhabilidade}

A molhabilidade é uma propriedade de superfície relacionada com reações físico-químicas que se estabelecem na superfície de contato entre sólidos e fluidos (Tiab \& Donaldson, 2004). Pode-se, ainda, definila como a "tendência que um determinado fluido apresenta de aderir a uma superfície sólida, quando em presença de outros fluidos não miscíveis". A compreensão do fenômeno de molhabilidade, os fatores que o controlam e seus efeitos em propriedades petrofísicas como pressão capilar, lei de archie, permeabilidade relativa são de extrema importância para 
a avaliação de sua influência na recuperação de óleo. Existem dois métodos experimentais para a obtenção de um índice de molhabilidade: Amott e USBM.

O método Amott pode ser dividir em três etapas básicas: $\left.1^{\circ}\right)$ saturação total das amostras com água de formação sintética; drenagem forçada (primária) da água com óleo morto até o Swi (realizado em centrífuga ou membrana); e envelhecimento das amostras por alguns dias em estufa para fins de restauração da condição original de molhabilidade da rocha. $2^{\circ}$ ) Embebição espontânea de água e determinação, através do volume de óleo deslocado, o volume de embebição espontânea de água $\left(\mathrm{V}_{\mathrm{a}}^{\mathrm{e}}\right)$. Neste passo, a amostra é colocada em ambiente de água e mede-se o óleo que é deslocado da amostra. Embebição forçada de água e determinação do volume de embebição forçada de água $\left(V_{a}^{f}\right)$. $\left.3^{\circ}\right)$ Drenagem espontânea de água e determinação, através do volume de água deslocada, o volume absorvido espontaneamente de óleo $\left(\mathrm{V}_{0}^{\mathrm{e}}\right)$. Neste passo, a amostra é colocada em ambiente de óleo e se mede a água que é deslocada da amostra; Drenagem forçada (secundária) de água e determinação do volume de óleo absorvido $\left(V_{0}{ }^{f}\right)$. Assim, define-se repectivamente 0 índice de molhabilidade Amott ao óleo $\left(I_{0}\right)$ e à água $\left(I_{a}\right)$ como:

$$
\mathrm{I}_{\mathrm{o}}=\mathrm{V}_{\mathrm{o}}^{\mathrm{e}} / \mathrm{V}_{\mathrm{o}}^{\mathrm{e}}+\mathrm{V}_{\mathrm{o}}^{\mathrm{f}} \quad \mathrm{I}_{\mathrm{a}}=\mathrm{V}_{\mathrm{a}}^{\mathrm{e}} / \mathrm{V}_{\mathrm{a}}^{\mathrm{e}}+\mathrm{V}_{\mathrm{a}}^{\mathrm{f}}
$$

Os índices $\mathrm{I}_{\mathrm{o}}$ e $\mathrm{I}_{\mathrm{a}}$ podem assumir valores entre 0 e 1 . $\mathrm{O}$ valor 1 indica uma condição extrema de molhabilidade: rocha fortemente molhável à água $\left(l_{a}=1\right)$ ou rocha fortemente molhável ao óleo $\left(l_{0}=1\right)$. Quando ambos os índices são iguais a zero, situação em que não se observou embebição natural de nenhum dos fluidos, dizse que a rocha apresenta uma condição neutra de molhabilidade. A molhabilidade mista é verificada quando os índices de molhabilidade ao óleo $\left(\mathrm{I}_{0}\right)$ e à água $\left(\mathrm{I}_{\mathrm{a}}\right)$ são parecidos mais distantes de zero, isto é, a rocha tem regiões molháveis ao óleo e, em quantidade semelhante, regiões molháveis à água. Nas situações em que a rocha sob estudo apresenta embebição tanto de água como de óleo, pode-se adotar como índice de molhabilidade Amott a diferença entre os índices $I_{a}$ e $I_{0} \quad\left(I=I_{a}-I_{0}\right)$, o qual representa a condição média de molhabilidade da rocha.

No método USBM (United States Bereau of Mines) são comparados os trabalhos necessários para a embebição primária $\left(A_{1}\right)$ e drenagem secundária $\left(A_{2}\right)$ da água. $A$ magnitude do trabalho é obtida pela área sob a curva de pressão capilar em função da saturação. O teste de molhabilidade para o método USBM segue as mesmas etapas do ensaio Amott porém com a obtenção completa das curvas de pressão capilar (na análise Amott, são necessários apenas os pontos terminais) e sem a embebição e drenagem espontâneas. O Índice de molhabilidade USBM é dado por:

$$
\mathrm{I}_{\text {USBM }}=\log \left(A_{2} / A_{1}\right)
$$

O teste de molhabilidade USBM tem como principal vantagem em relação ao teste Amott a maior sensibilidade para amostra com molhabilidade neutra, mas com a desvantagem de não conseguir diferir entre molhabilidades neutra e mista. É possível que em uma mesma sequência de análise se obtenham ambos os índices no que se conhece como método combinado
Amott/USBM. A seqüência de procedimentos é a mesma descrita para o teste USBM, porém com as etapas de embebição e drenagem espontâneas. O índice Amott obtido nesta análise combinada não difere em nada do índice obtido em separado. O índice USBM pode ser um pouco diferente porque a região da curva de pressão capilar que é obtida espontaneamente (pressão capilar quase nula) não contabiliza trabalho.

\section{Conclusões}

Seguindo-se um típico fluxo de trabalho na indústria do petróleo, demonstrou-se como os principais parâmetros petrofísicos são obtidos em laboratório. Embora não se tenha a pretensão de esgotar o tema, abordou-se a importância das técnicas laboratorias para caracterização qualitativa e quantitativa das rochas reservatório. Podese dizer que, de forma análoga a medicina, os ensaios laboratoriais dão o diagnóstico sobre a qualidade e o potencial produtivo de uma rocha. Uma vez que as condições do sistema são conhecidas e bem controladas, minimizando-se os erros experimentais, os dados gerados em laboratório constituem a informação petrofísica mais direta e confiável, muitas vezes indisponíveis em campo. Com uma interpretação cuidadosa e o correto escalonamento dos dados laboratoriais, os dados de campo podem ser calibrados para geração de um modelo geológico mais realista, auxiliando nas tomadas de decisões durante a exploração e explotação de um reservatório.

\section{Agradecimentos}

CNPQ e PETROBRAS pelo apoio financeiro. Ao Laboratório de Petrofísica do Cenpes pela utilização das figuras e aos técnicos deste mesmo laboratório pela troca de experiências práticas.

\section{Referências}

SCHON JH. 2004. Physical properties of rocks: fundamentals and principal of petrophysics. Elsevier, Amsterdam, 583pp.

VASQUEZ G, JUSTEN J, MORSCHBACHER M. 2011. Aplicações da Física de Rochas na Exploração e Produção de Petróleo. Em Boletin SBGF Número 1 - ISSN 2177-9090.

FREIRE R, NASCIMENTO AC, DENICOL PS, BENEDUZI C. 2010. Fluxo de trabalho na avaliação petrofísica de poços. Em Simpósio Brasileiro de Geofísica, SBGF2459, Brasília, DF, Brasil

TIAB D, DONALDSON EC. 2004. Petrophysics: Theory and Practice of Measuring Reservoir Rock and Fluid Transport Properties, 2 ed., Elsevier.

ROSA AJ, CARVALHO RS \& XAVIER JAD. 2006. Engenharia de Reservatórios de Petróleo. Rio de Janeiro: Editora Interciência.

AMERICAN PETROLEUM INSTITUTE. 1998. Recommended practices for core analysis. Recommended Practice RP40, 2nd ed., $220 \mathrm{pp}$.

RIOS EH. 2011. Caracterização Petrofísica de Rochas Reservatório por RMN: Abordagem Clássica e Modelos Multivariados. Dissertação de Mestrado, Observatório Nacional. 